\title{
Convergence of employers' and students' expectations in the educational environment of the agricultural university
}

\author{
Elena Razinkina ${ }^{1}$, Elena Zima ${ }^{1}$, Elena Pozdeeva ${ }^{1}$, Lidiya Evseeva $^{1}$, and Anna Tanova ${ }^{1, *}$ \\ ${ }^{1}$ Peter the Great St. Petersburg Polytechnic University, 195251 St.-Petersburg, Russia
}

\begin{abstract}
In the digital age, a modern university is becoming a driver for the development of complex multi-agent ecosystems and a supplier of a new type of human resources, characterized not only by intellectual potential and high qualifications but also by such qualities in demand in the labor market as creativity, critical thinking, the need for continuous learning and "agency", which is understood as the ability to self-organize and proactivity [1]. The education system and universities themselves face challenges that force us to turn to the once-actual ideas of integration and convergence, which can fulfill the increased need to achieve synergy effects and multiplier indicators that contribute to achieving high ratings in a short time. It is convergent processes that lie at the heart of the developing communicative space of the university today, whose activities are based on the intersection of the interests and expectations of various actors, which are implemented on multi-agent platforms. At the same time, the opportunities that are opening up due to the rapid introduction of digital technologies require restructuring the space of interactions between subjects towards the formation of flexible forms, network models, alliances, virtual corporations, connecting clusters built on the principles of active cooperation, exchange of best practices and developments.
\end{abstract}

\section{Introduction}

A new look at the transformations taking place in the context of the transition to a new technological order focuses on the processes of convergence, which in the world of everyday life are already deeply rooted in media culture on the basis of the interpenetration of media systems [2]. These processes are based on technological convergence, which is defined as the tendency of various technological systems to develop in the direction of solving common problems [3]. In relation to the educational space, convergence acts as a process of interpenetration of educational technologies and strategies of agents of the educational process, combination of communication networks and content that implement the educational policy of the university, accompany the provision of educational and research services, and promote the interaction of the university with the environment.

The university as a convergent system is formed as a result of the interaction of network structures that allow the implementation of educational services, attracting partner resources,

${ }^{*}$ Corresponding author: tanovaann@mail.ru 
programs and projects within the framework of ongoing scientific developments and advisory activities. The participants in the interactions are, first of all, representatives of the university, students and partners, among whom there are potential employers. The role of the university follows from its leadership positions in the educational space, as well as the mediation functions of regulating direct and indirect interaction with participants in the educational process. The university as a communicator deals with the accumulation of information and analysis of data on the requests and expectations of students, on the one hand, as well as on the requirements and expectations of potential employers. The coincidence of the expectations and attitudes of both parties, the desire to optimize the educational potential of a graduate entering the labor market after graduation, provides the forces of convergence of behavioral strategies in the communicative space, which is part of the educational space. Based on the available data obtained through sociological surveys, the university, as a communicator, develops behavioral strategies in order to implement the identified requests and its own educational policy.

\section{Materials and methods}

As J. Urry noted, we live in a world of mobility, in which the boundaries between the local and the global are becoming more and more blurred, they form a symbiotic, irreversible, unstable system of connections [4].

The classical approach to the concept of convergence in the social sciences is based on the ideas of P.A. Sorokin, J. Galbrayte, who turned to the analysis of objective processes of social systems convergence and the construction of a new post-industrial society, which has the features of optimality and the advantages of opposite socio-economic structures $[5 ; 6] \mathrm{M}$. Castells singles out the increasing "convergence of specific technologies in a highly integrated system, in which old, isolated technological trajectories become literally indistinguishable" as one of the key characteristics of the modern stage of the information society development [7] According to O.I. Yanitsky, hybridization is becoming "the mainstream of social dynamics and its scientific and technical tools", it is a "fusion" of agents of different quality, structures and processes of social action, which contributes to the formation of sociobiotechnical systems [8] Today, a complex system is taking shape, which is formed as a result of the synthesis of a wider range of components; it is based on NBICconvergence - a combination of the achievements of nano-, bio-, information and cognitive technologies. New technologies also define a convergent model of an intelligent educational environment (Smart Learning Environment - SLE), in which learning systems, technologies and resources are integrated using e-learning, m-learning, cloud learning, blended learning and ubiquitous education. Thus, the convergent approach presupposes the systemicsynergetic integration of all elements and processes [9].

Convergence processes in education are based on the integration of scientific knowledge and technological advances, including communication technologies, which makes it possible to integrate interdisciplinary connections, new approaches and technologies to the development and implementation of educational programs and to form flexible skills of students.

Many authors believe that today a breakthrough in education can be provided by the convergence of neuropsychology, cognitive, information and communication and pedagogical technologies [10]. Convergence processes accompany the development of an interdisciplinary approach in the formation of graduate competencies $[11,12]$. Convergent education from the standpoint of cognitive technologies leads to the transformation of pedagogical technologies, bringing projective and constructive activity to the fore [13].

The educational environment of the university, considered as a resilient system [14], allows to form a new attitude to educational results, which emphasizes their stability in 
various conditions and under the influence of situational factors [15]. Resilience of educational results corresponds to satisfaction with learning, and allows us to treat the educational environment of the university as sustainable in providing the necessary resources to achieve educational goals. The principle of resilience contributes to the development of an approach to the design of educational interactions, based on the conditions of the variability of communication practices and flexibility of strategies.

Convergence in communications characterizes the process of converging at one point of the participants' intentions, as well as communicative elements, channels arising from common needs, attitudes, interests, goals, common themes reflecting interest in communication. The convergent nature of communication arises from the coincidence of the constituent elements, their common characteristics, which provides a convergence field - a conditional situation of maximum convergence of strategies, which acts under the influence of the contextual environment, involving participants in communication and prompting to organize a place of communication in space.

In this regard, the theory of communicative adaptation also works, in which convergence is one of the strategies by which communication participants adapt to each other's behavior, taking into account common goals, the desire for socially approved behavior and effective results.

In convergent systems, the main character is the agent, the subject of relations, possessing effective subjectivity with the inherent qualities of decision-making autonomy and design of his own activity. The approach to the participant in relationships from the standpoint of effective subjectivity, developed by E. Vnuk-Lipinsky, emphasizes the personal qualities of the participant - such as a high level of consciousness, free will and reflexivity, initiative, creativity, a sense of control over one's own behavior and a sense of effectiveness, which is associated with attribution their actions the expected consequences [16].

The concept of "agency" by K. Evans [17] is combined with the approach of effective subjectivity, which means the subject's ability to long-term planning of his own life strategy. In modern educational models that reveal the possibilities of individualization of education, the ability to act underlies the formation of the graduate's integral competence, expressed in his ability to build and manage his own life trajectory [18]. A. Bandura included goal-setting, calculation and planning, self-regulation and belief in self-efficacy in the system of elements of the ability to act [19].

The convergent nature of the interaction of subjects who meet in the educational space of the university can also be analyzed from the standpoint of the motivation model for altruistic behavior, which is based on identifying attitudes towards cooperation and mutual reinforcement of optimal behavioral strategies. The integral principle, mutual "adjustment" and coordination of expectations and actions invariably become the driving forces of the evolution of relationships, determine the positive dynamics of the development of social systems. Today the concept of "altruism" is often used synonymously with the concepts of "cooperation", "mutual assistance", "mutual support". Individualism (Z. Bauman) and egoism as antipodes of altruism can be considered as dialectical components, the synthesis of which gives rise to such a phenomenon as "egoistic altruism" [20], its motive is the underlying and often latent desire to receive benefits as a result of social exchange, which provides a rational basis for development systems of interactions.

Thus, the driving force of changes in the communicative space of the university educational environment is the current tension caused both by the desire of agents to achieve their own goals and to maximize the effects of their achievement, and by the convergent attraction to cooperation, which allows for a valuable selection of the most suitable personnel for professional work. 


\section{Results}

The empirical basis of this work is a number of sociological surveys conducted at Peter the Great St. Petersburg Polytechnic University, including monitoring ones devoted to the problems of student satisfaction with the quality of education, as well as surveys of alumni and employers.

Monitoring surveys dedicated to assessing the quality of education and satisfaction with training show the correspondence of the education received at the university in the direction / specialty to the student's expectations, as well as the formed strategies for further employment in accordance with the qualification / specialty received.

Thus, the results of the 2019 survey (the survey was conducted from May 30 to June 30, 2019 , the sample consisted of 3,878 students) showed a high level of student satisfaction with their education $-72 \%$ [21]. There is a positive trend in the indicators of satisfaction, compliance with expectations and a reflection of the intention to work in the specialty (see Table 1).

Table 1. Learning Satisfaction Indicators.

\begin{tabular}{|c|c|c|c|}
\hline & $\mathbf{2 0 1 7}$ & $\mathbf{2 0 1 8}$ & $\mathbf{2 0 1 9}$ \\
\hline Overall satisfaction with learning & $66 \%$ & $67 \%$ & $72 \%$ \\
\hline Learning meets expectations & $65 \%$ & $66 \%$ & $67 \%$ \\
\hline $\begin{array}{c}\text { Are going to work in their } \\
\text { specialty after graduation }\end{array}$ & $64 \%$ & $66 \%$ & $64 \%$ \\
\hline $\begin{array}{c}\text { Have an idea of who they will } \\
\text { work for }\end{array}$ & $68 \%$ & $48 \%$ & $\begin{array}{c}\text { question } \\
\text { excluded }\end{array}$ \\
\hline
\end{tabular}

Also, students demonstrated a fairly high level of satisfaction on a scale from 1 to 5 , where 1 is not at all satisfied, 5 is absolutely satisfied, and 0 is difficult to answer, for the following blocks of disciplines listed in Table 2 (see Table 2).

Table 2. The level of satisfaction with discipline blocks.

\begin{tabular}{|c|c|c|c|c|c|c|}
\hline & \multicolumn{7}{|c|}{ The level of satisfaction (\%) } \\
\hline Discipline blocks & $\mathbf{0}$ & $\mathbf{1}$ & $\mathbf{2}$ & $\mathbf{3}$ & $\mathbf{4}$ & $\mathbf{5}$ \\
\hline Computer techologies & 10 & 11 & 13 & 24 & 24 & 18 \\
\hline Foreign languages & 4 & 9 & 12 & 24 & 31 & 20 \\
\hline General professional disciplines & 3 & 5 & 7 & 24 & 39 & 22 \\
\hline $\begin{array}{c}\text { Disciplines of a profile } \\
\text { (specialization) }\end{array}$ & 8 & 7 & 7 & 11 & 23 & 44 \\
\hline Natural science disciplines & 7 & 7 & 9 & 17 & 31 & 29 \\
\hline Socio-humanitarian disciplines & 5 & 10 & 12 & 22 & 29 & 22 \\
\hline
\end{tabular}

The skills acquired in the framework of teaching computer technology, general professional and profile, as well as natural science and socio-humanitarian disciplines, can be attributed to hard, and the skills of foreign languages for students, mainly not related to linguistics, are more likely to be soft.

This correlates with the satisfaction of SPbPU graduates, who were surveyed in May 2020, on the hard skills they have acquired.

A survey of graduates revealed a fairly high level of compliance of the skills and abilities acquired at the university with the requirements for graduates in the workplace (Fig. 1-3). This reflects a sense of awareness of the professional work basics among graduates. 


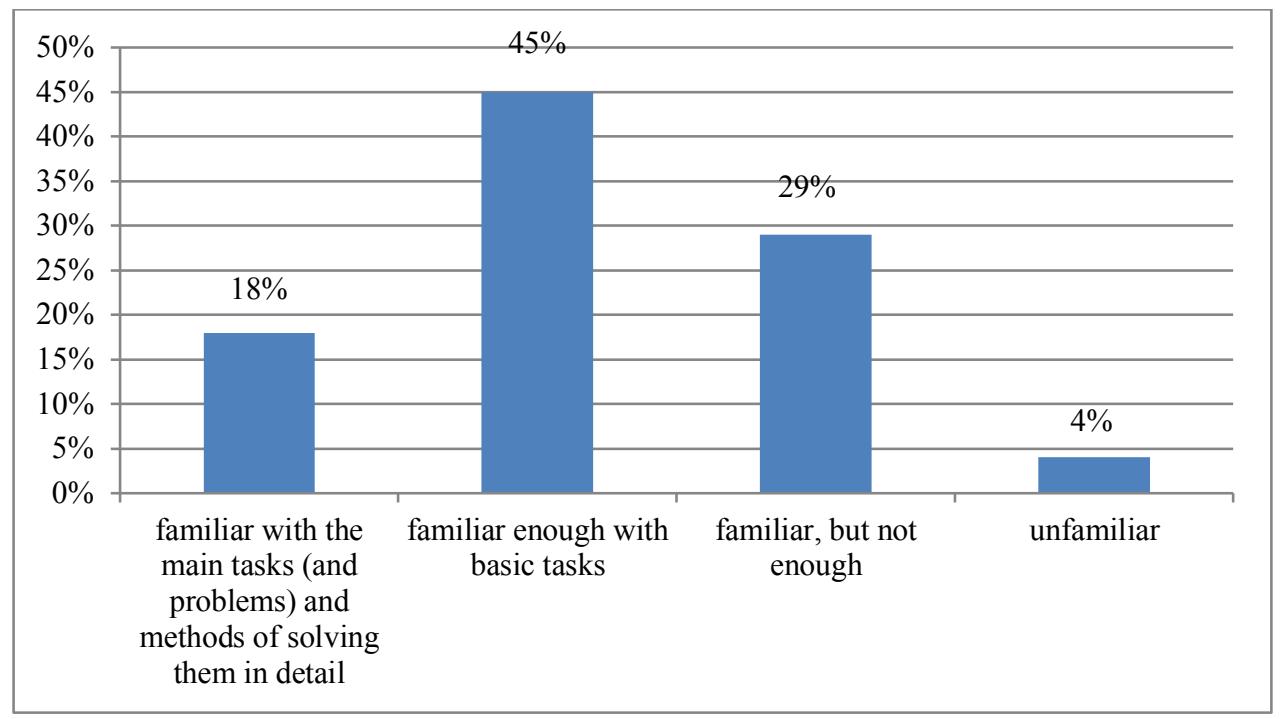

Fig. 1. How familiar were you with the tasks and (or) problems of your future professional career?

An analysis of the respondents' answers to this question shows that almost half of the graduates $(45 \%)$ are quite familiar with the main tasks and possible problems of their future professional activities, $29 \%$ indicated insufficient acquaintance, and 18\% are thoroughly aware of the main tasks and methods of solving problems in the framework of the future profession. Accordingly, more than half of the graduates - $63 \%$ - announced their acquaintance with the tasks that they will have to solve in the workplace.

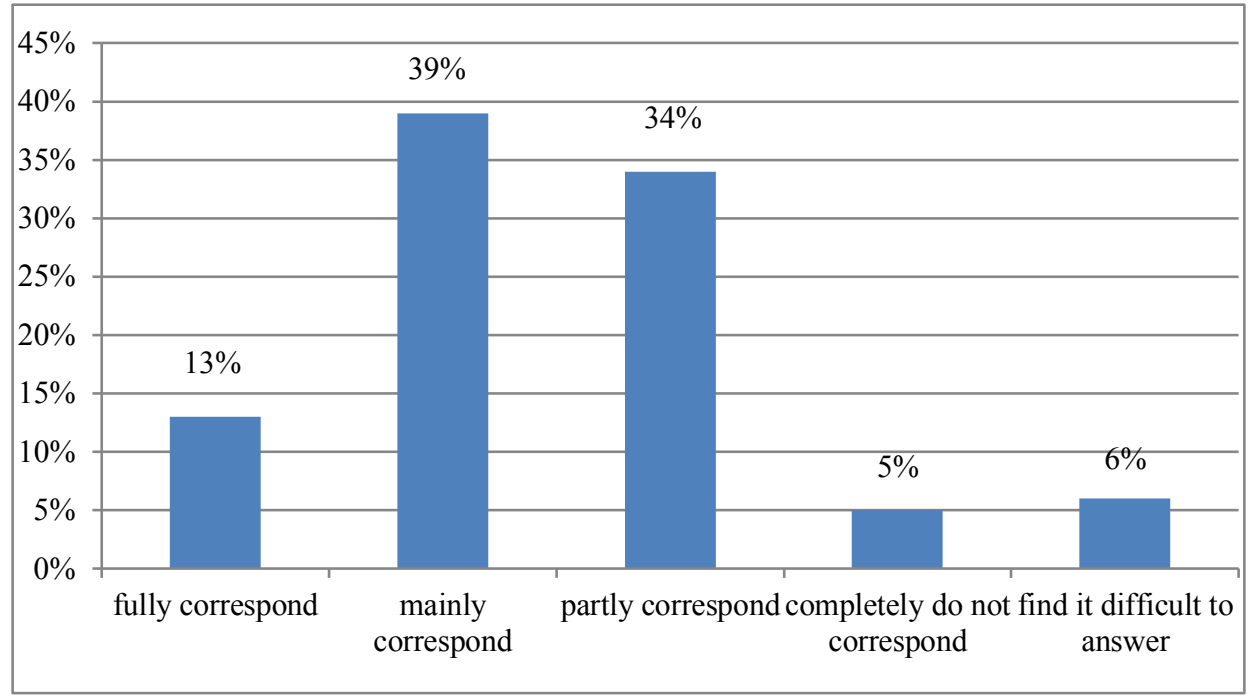

Fig. 2. To what extent do the competencies formed during the development of an educational program in the direction of training (specialty) correspond to your professional activity?

In total, $86 \%$ of graduates stated that the competencies formed during the development of an educational program in the field of training (specialty) corresponded to their professional activities. The fact that the university prepares specialists focused on the requirements of employers and the modern labor market emphasizes its leading role as a communicator in the educational and professional space. 


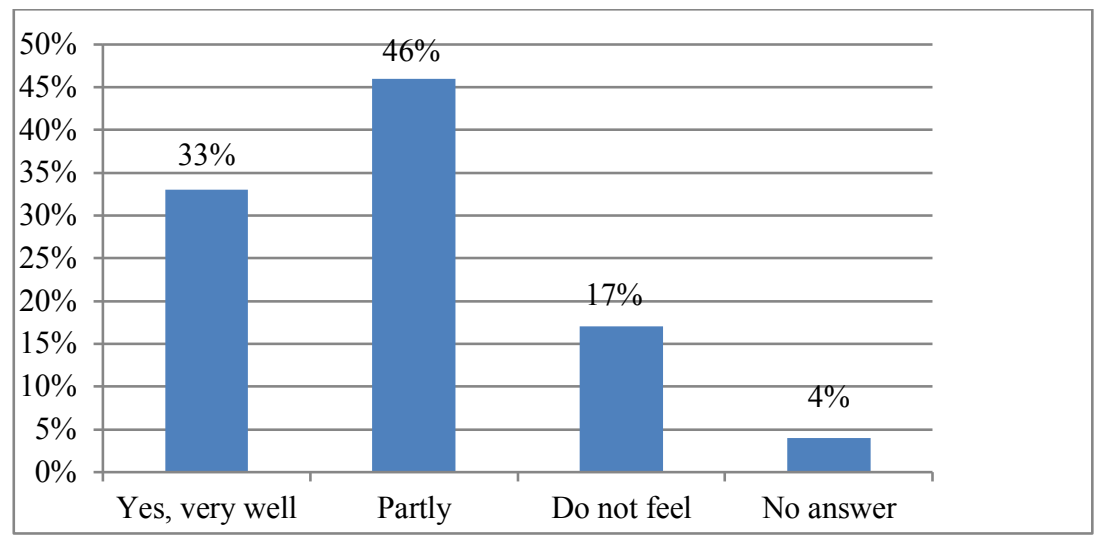

Fig. 3. Do you feel prepared for independent work in your professional activity?

$79 \%$ declared full $(33 \%)$ or partial $(46 \%)$ preparation for independent work in their specialty.

Also, the overwhelming majority of respondents - 80\% - noted the compliance (to varying degrees: $12 \%$ - complete, $30 \%$ - mainly and 38\% - partial) of the practical skills acquired at the university with the requirements for employment. A significant part of the respondents (86\%) indicated the compliance (to varying degrees: $19 \%$ - for full, $39 \%$ - for basic, and $28 \%$ - for partial) university theoretical training with the requirements of employers. All this shows that the "hard" or professional skills of graduates are fully formed.

In May 2020. a survey of employers was also conducted. Alumni and employer surveys were conducted using the online survey method in order to study the satisfaction of graduates with their education at the university, possible employment problems, and also to compare the indicators of graduate satisfaction with the indicators of employers' satisfaction with the quality of education of university graduates whom they recruit. The sample of graduates was 980 people, and employers - 68 respondents.

When answering the question "To what extent do the graduates' competencies, formed during the development of an educational program, correspond to professional standards (if any)??" $65 \%$ of the respondents indicated that they correspond ( $16 \%$ fully correspond, mainly correspond $49 \%$ ), $23 \%$ of respondents indicated partial compliance, and no one chose the option "completely do not correspond". 12\% did not answer this question (Fig. 4).

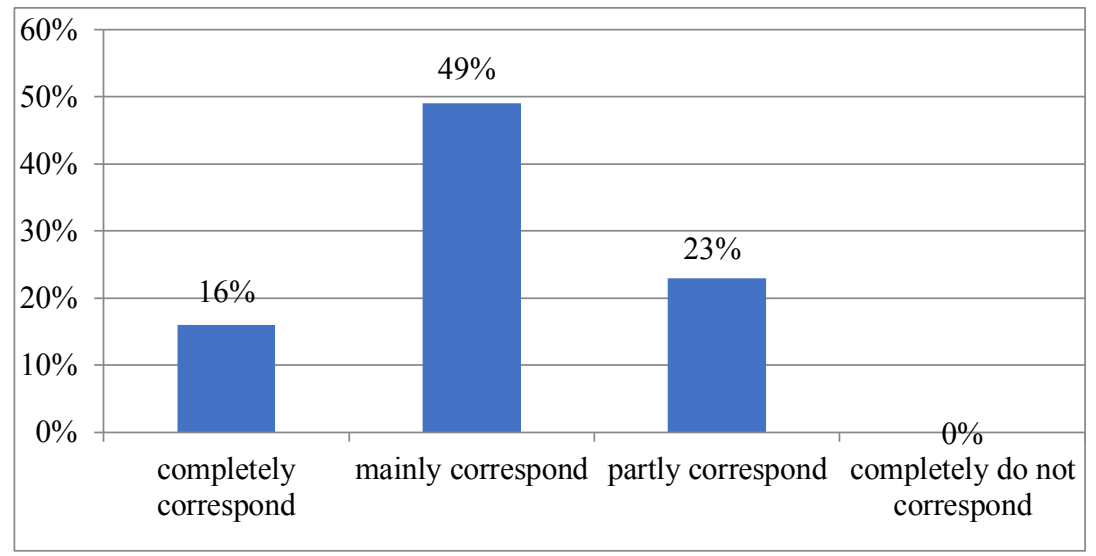

Fig. 4. To what extent do the graduates' competencies, formed during the development of an educational program, correspond to professional standards (if any)? 
The survey also showed a high degree of employers' satisfaction with the quality of graduates' training, since the assessment of the level of graduates' training is in the interval "average and above average". This assessment is integrated from indicators of assessment of knowledge, skills and abilities demonstrated by graduates: satisfaction with the level of their theoretical (Fig. 5) and practical (Fig. 6) training, formed communication skills (Fig. 7) and teamwork abilities (Fig. 8).

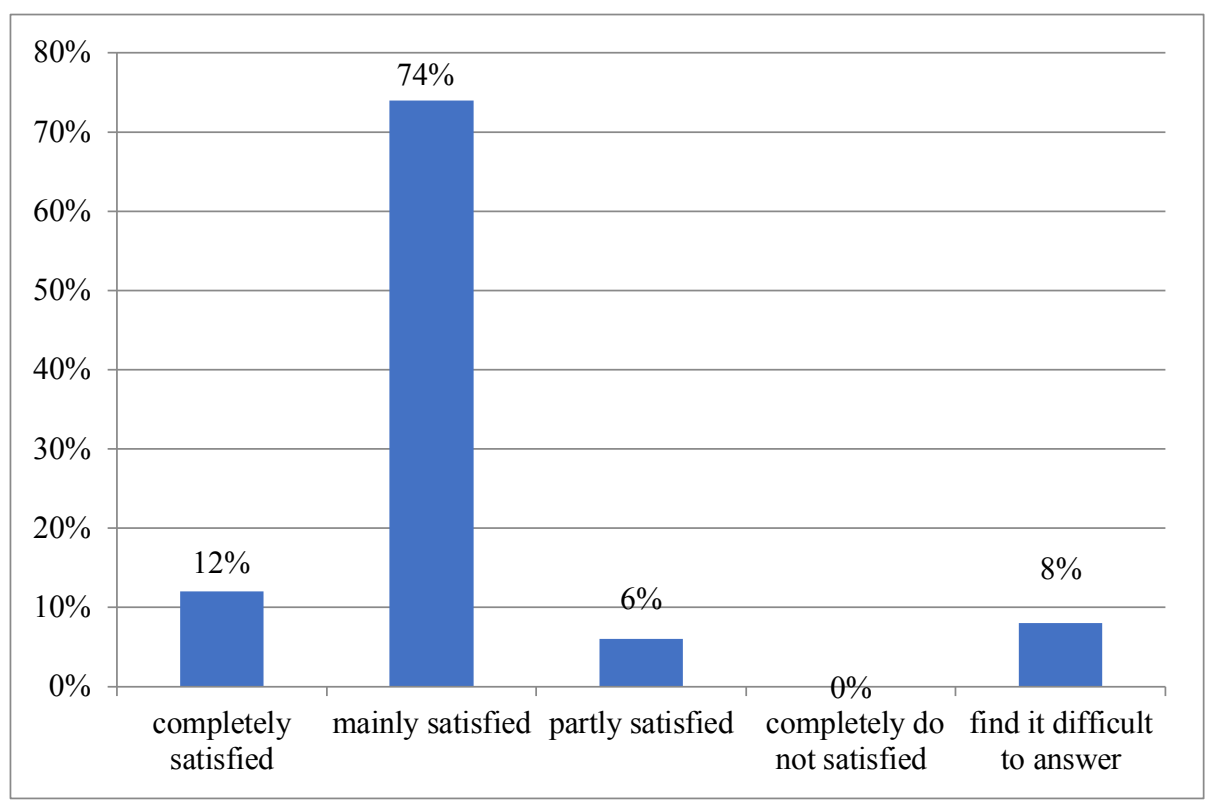

Fig. 5. How satisfied are you with the level of theoretical training of graduates?

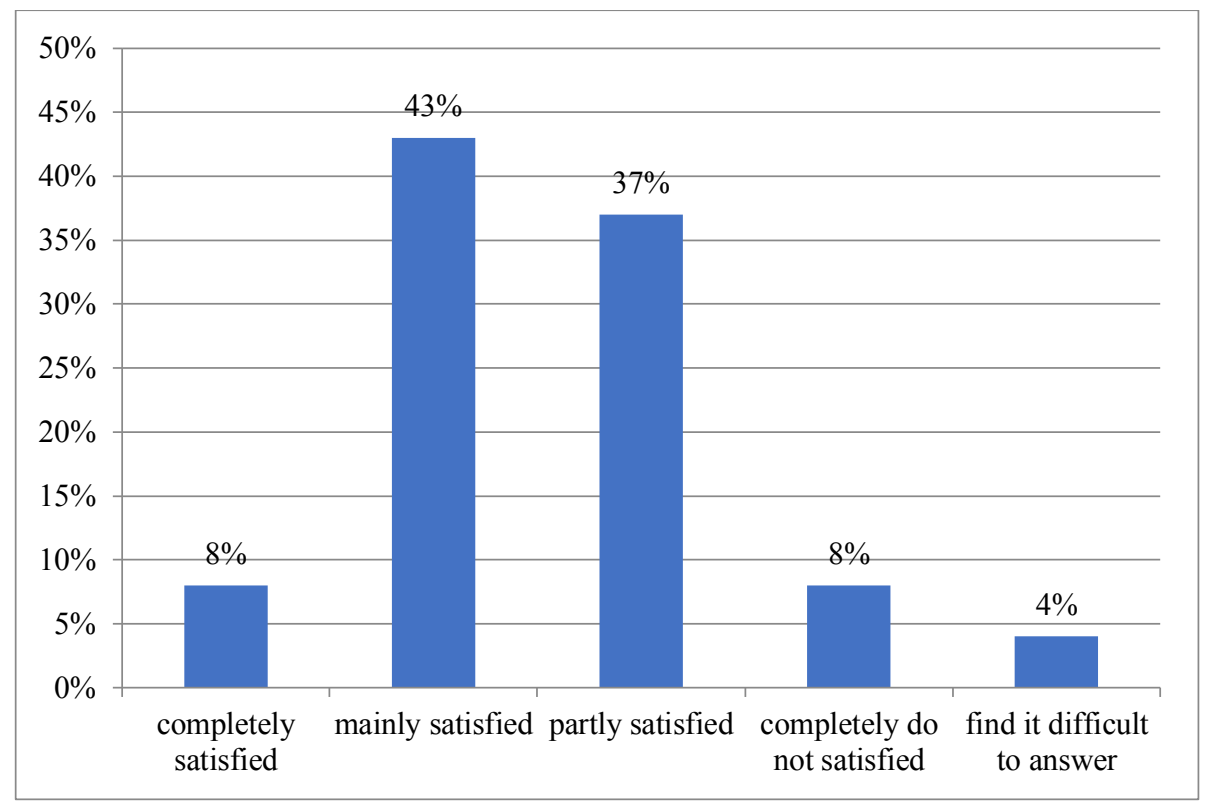

Fig. 6. How satisfied are you with the level of practical training of graduates? 
Employers' answers about the theoretical and practical training of graduates correlate with a high assessment by the graduates themselves of the degree of their preparedness for work. $86 \%$ of surveyed employers are satisfied with the level of theoretical training of graduates, and half - 51\% - are completely or mainly satisfied with the level of their practical training.

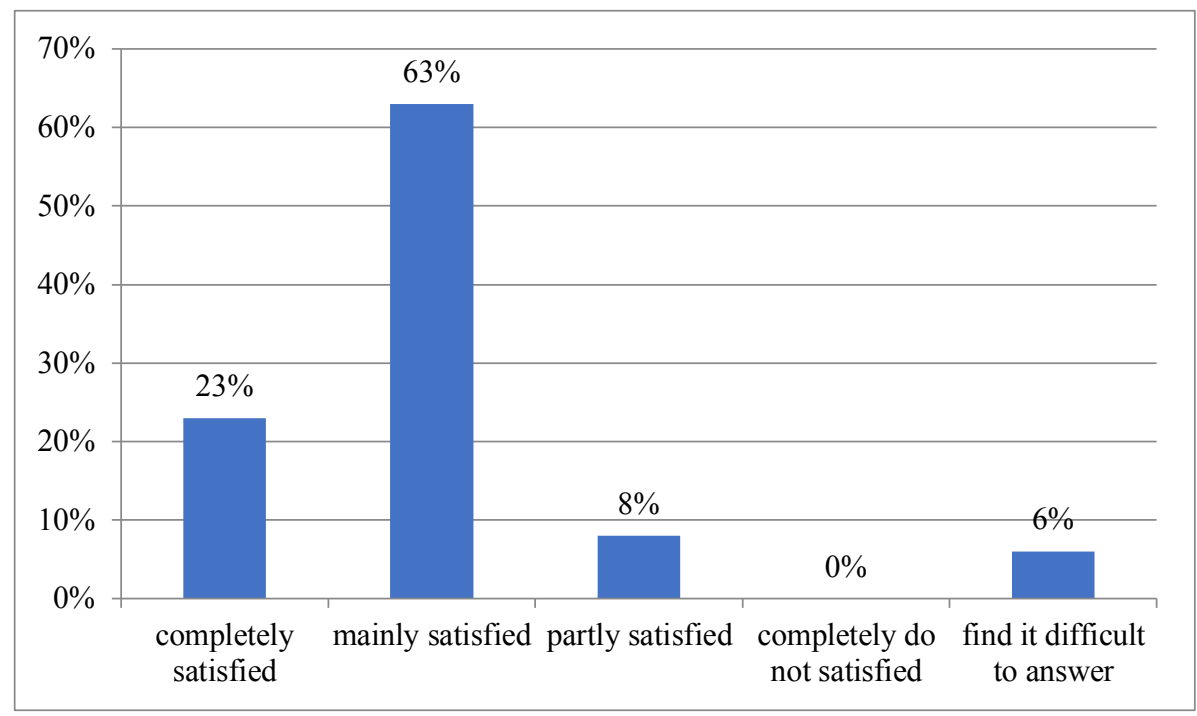

Fig. 7. How satisfied are you with the communicative qualities of the graduates?

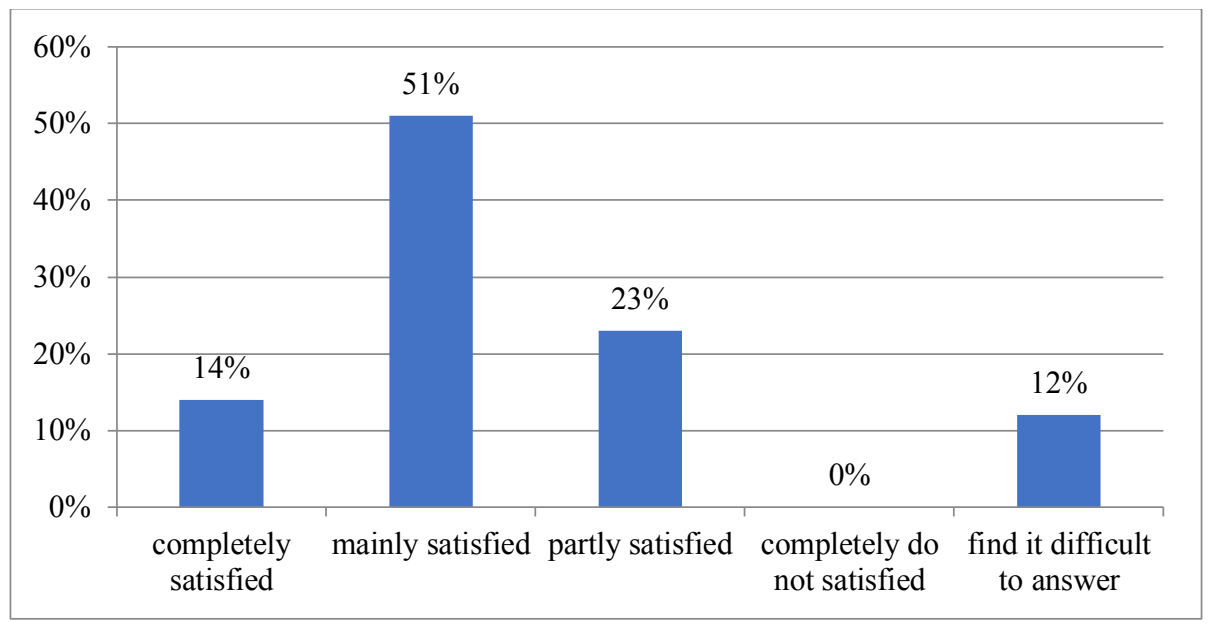

Fig. 8. How satisfied are you with the graduates' teamwork abilities and leadership qualities?

The majority of employers demonstrated satisfaction with the communication skills of graduates $(86 \%)$, their teamwork abilities and their leadership qualities $(65 \%)$. Taking into account the fact that more than half of employers are also satisfied with the ability of graduates for systemic and critical thinking (69\%), for the development and implementation of projects (59\%), as well as for self-organization and self-development $(67 \%)$, the results obtained indicate that the university is a leader not only in the formation of hard skills of graduates, as noted above, but also soft skills, which are an integral part of the professional competence of a modern specialist, regardless of the field of his professional activity.

An analysis of employers' responses shows that a small part of employers is "completely dissatisfied" with the following skills and abilities of graduates: 10\% - their abilities for 
systemic and critical thinking and $8 \%$ each - with the ability to develop and implement projects and the level of practical training. This may indicate the need to develop the work of the university in these areas.

Also, as a result of the survey, it became clear that employers would like to get a readymade specialist after university who is familiar with the specifics of work in industries. At the same time, employers see their cooperation with the university more in providing students with internships, in participating in joint projects within small enterprises organized on the territory of the university, but to a lesser extent employers are inclined to take part in the activities of commissions for final certification or in accreditation activities. But this is important, as it allows the university to timely update the main educational programs. In general, the results of the survey demonstrate a fairly high communication activity of employers and representatives of SPbPU, as well as contact between employers and students in the development of educational programs.

Summarizing the empirical information obtained as a result of the surveys, we can formulate the following conclusion. Both employers, when assessing the quality of graduates 'training, and graduates, when assessing satisfaction with the education received at the university, demonstrate a fairly high level of satisfaction, however, they emphasize the need to strengthen the practical orientation of programs in the formation of graduates' competencies, to take into account industry specifics in theoretical and practical training. Also, employers, in addition to professional qualities, highly value graduates for their communicative competencies, teamwork skills, initiative and ability for self-management and self-development. Graduates today particularly highlight these flexible skills as the strengths of the training they have received.

Thus, convergent trends in the development of the general field of expectations, including an emphasis on operational industry knowledge and skills in mastering new technologies, communicative activity and initiative, the implementation of the team principle in activities, turn out to be important factors in adjusting further strategies for university development.

\section{Discussion}

Among the studies by Career.ru, dedicated to the problem of monitoring changes in employers' requests in relation to graduates, a survey (2018) was carried out among employers and HR specialists involved in recruiting. The company found out how actively employers interact with educational organizations to prepare and attract graduate students. The survey showed that $63 \%$ of companies interact in one way or another with organizations of higher and secondary education, $44 \%$ of companies that do not cooperate with educational institutions at present plan to start such work in the future. The main goal of this interaction was noted - it is the search for high-potential students $(65 \%)$. Other urgent tasks were the replenishment of the personnel reserve $(57 \%)$, attracting students to practice $(51 \%)$ and increasing the company's brand awareness in the labor market (51\%) (see Fig. 9) [21]. 


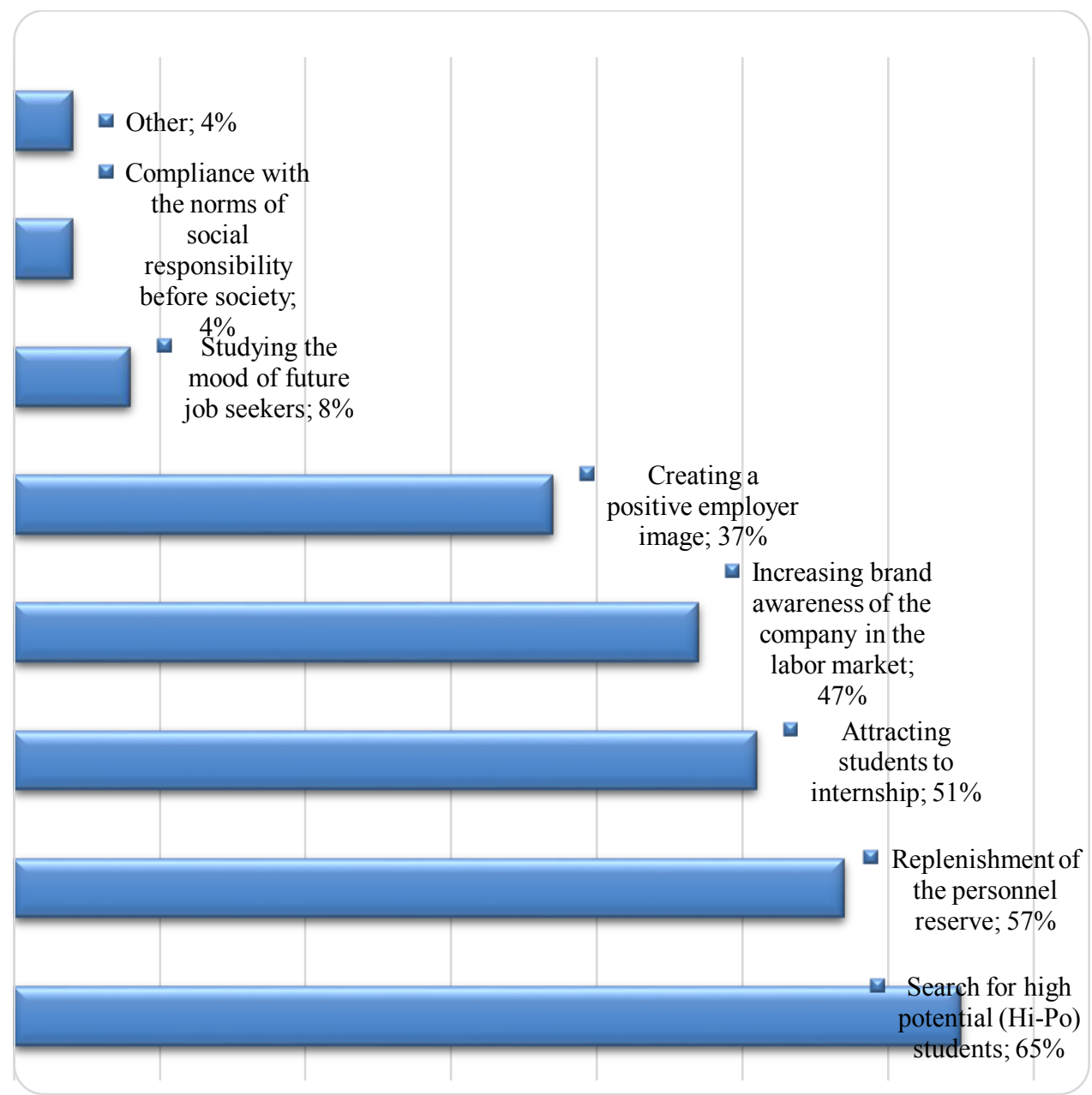

Fig. 9. What goals does your company pursue when interacting with an educational institution [https://spb.hh.ru/article/22034].

Based on the survey data, Career.ru claims that almost half of the surveyed Russian employers indirectly confirm the need for interaction between employers and university representatives for business development. Practices and internships for students were named the most common tool for interaction ( $80 \%$ ); among the respondents, $65 \%$ of company representatives called internships for students the most effective tool for interacting with universities. At the same time, a tendency emerged - according to a third of the respondents, regular sections and master classes are a more effective tool for interacting with educational institutions as compared to one-time events.

Another trend concerns the influence of the size and level of a company on its need for active communication with universities: here, as the number of employees increases, the share of companies cooperating with educational institutions increases: $78 \%$ of large companies, $64 \%$ of medium-sized and $43 \%$ of small ones have already established such cooperation (Fig. 10). 


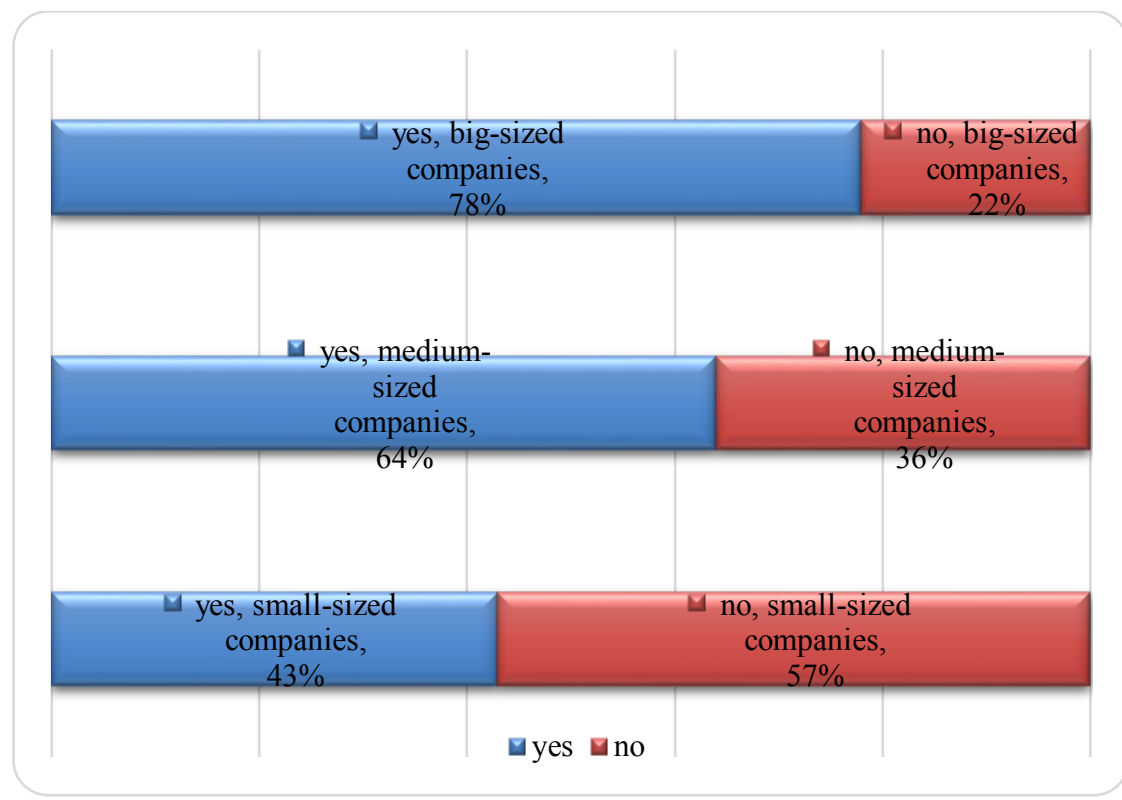

Fig. 10. Does your company interact with educational institutions? [https://spb.hh.ru/article/22034].

Based on the comparison of sociological data, it is possible to accentuate the basic problems identified by a number of authors in the study of the employers' and graduates' expectations. This is the problem of the influence of varying degrees of competitive environment deformation, that is characteristic of the entire sphere of economic relations, as well as the influence of disparities in wages in a number of sectors of the economy (primarily in the budget), as well as the problem of maintaining the differentiation of the educational services quality in different universities of the country.

Graduates admit that the main criteria for the placement of a young worker differ depending on the field of activity: for state, budgetary organizations, such criteria are the results of the interview (testing) and work experience in the organization's profile, and for commercial structures - personal qualities and work experience in the organization's profile. At the same time, work experience is in the first place among those characteristics that employers pay attention to.

Also, according to surveys of employers, more than half of them consider it expedient to participate in the development of training programs for specialists in their profile (educational standards, topics of diploma theses and projects, etc.), and also declare their willingness to share knowledge on new technologies of professional activity with teachers [22].

Myagkov A.Yu. notes that not only university training is in need of significant modernization today, which continues to be largely focused on the breadth and universality of education, but also the labor market, from the point of view of the inclusion of competitive mechanisms of employment and subsequent career advancement of workers [23, p. 107-108]. Despite some discrepancies in the rating of requirements, the main guidelines for employers remain professional training of a graduate, work experience and the ability to develop their "social capital". And the formation of adequate ideas and expectations is an important component of the educational work of the university.

Thus, the problem of analyzing the emerging gap in the perceptions and expectations of employers and graduates, according to a number of studies [24], is today in the first place of the research agenda, since not all graduates have an adequate assessment of their readiness for professional and personal development. Also, their knowledge of what skills, skills and 
competencies the employer wants to see is sometimes far from the reality of the modern market.

\section{Conclusions}

Studies of the processes reflecting the expectations and positions of graduate training participants from both the university and the employer show convergent trends: the field of discussion of the skills and competencies of the graduate requires more and more openness, a request has been formed for an integrated set of modern knowledge and skills of the university graduate, communication is required in the development of methodological support and in the learning process with a higher level of customer participation. Thus, it can be confirmed that a modern university is increasingly taking a course to align the expectations of employers and graduates, to develop partnerships with business and other representatives of the customer, providing opportunities to combine university knowledge with practical skills [25]. This stimulates both the transfer of knowledge and the development of new communicative models of interaction in the developing educational space.

In conclusion, we would like to once again emphasize the role of the university as a convergent system, formed, inter alia, in the course of interaction with partner resources of employers. Studies have shown that a high degree of student satisfaction with the skills acquired during their studies at the university correlates with satisfaction with the skills of graduates, which confirms the leading role of the university as a communicator when interacting with significant environmental agents. As a result of this interaction, the parties discover and agree on mutual requirements and expectations, which allows both students (future graduates) and employers to adjust their behavioral strategies in the common communicative space. Within this space, each side tries to maximize its effects - senior students and graduates find work in a specialty that best meets their expectations, and employers - to involve young specialists in the labor process that best meet their requirements for theoretical knowledge and practical skills for work in the professional field.

\section{References}

1. Ya. Kuzminov, P. Sorokin, I. Froumin, J. Foresight and STI Governance 13(2), 19-41 (2019) DOI: 10.17323/2500-2597.2019.2.19.41

2. H. Jenkins, Convergence Culture: Where Old and New Media Collide (New York University Press, New York, 2006) ISBN 0-8147-4281-5

3. A. Elliott, J. Urri, Mobile Lives (Routledge, London and New York, 2010) ISBN 9780415480222

4. M. Castells, The Internet galaxy. Reflections on the Internet, business and society (Oxford University Press, 2001)

5. O. I. Yanitsky, Sociological studies 8, 8-17 (2019) DOI: 10.31857/S0132162500061328

6. N. Almazova, D. Bylieva, V. Lobatyuk, A. Rubtsova, SPBPU IDE'19: Proceedings of Peter the Great St. Petersburg Polytechnic University International Scientific Conference on Innovations in Digital Economy (ACM, New York, 2019) https://doi.org/https://doi.org/10.1145/3372177.3373340

7. I. Obukhova, D. Popov, A. Tanova, V. Fokina, E3S Web of Conferences 164, 12010 (2020) https://doi.org/10.1051/e3sconf/202016412010 
8. L.I. Evseeva, O.D. Shipunova, E.G. Pozdeeva, I.R. Trostinskaya, V.V. Evseev, DSIC 2019. Advances in Intelligent Systems and Computing. Springer, Cham AISC 1114, 241251 (2020) https://doi.org/10.1007/978-3-030-37737-3_22

9. T. Nam, TPACEE-2019: E3S Web Conferences 164, 12007 (2020) https://doi.org/10.1051/e3sconf/202016412007

10. T.L. Blinova, Pedagogical Education in Russia J 8, 42-48 (2018) DOI: 10.26170/po1808-06

11. M.V. Deev, A.G. Kravets, A.G. Finogeev, J. Fundamental research 12-1, 52-57 (2017) http://www.fundamental-research.ru/ru/article/view?id=41978

12. O.D. Shipunova, I.P. Berezovskaya, N. Smolskaia, ACM International Conference Proceeding Series. Proceedings of the Seventh International Conference on Technological Ecosystems for Enhancing Multiculturality, 745-750 (León, Spain, 2019) DOI: https://doi.org/10.1145/3362789.3362884

13. D.G. Arseniev, I.R. Trostinskaya, E.G. Pozdeeva, L.I. Evseeva, SPBPU IDE'19: Proceedings of Peter the Great St. Petersburg Polytechnic University International Scientific Conference on Innovations in Digital Economy, 60 (2019) https://doi.org/10.1145/3372177.3377547

14. L.B. Reichelhaus, Yaroslavl Pedagogical Bulletin J. 4 (2019) DOI 10.24411/1813145X-2019-10446

15. E. Vnyk-Lipinsky, Sociology of public life (Thought, Moscow, 2012)

16. K. Evans, Journal of Youth Studies 5(3), 245-269 (2002) https://doi.org/10.1080/1367626022000005965

17. E. Razinkina, L. Pankova, E. Pozdeeva, L. Evseeva, A. Tanova, E3S Web Conference 164, 12008 (2020) DOI: https://doi.org/10.1051/e3sconf/202016412008

18. A. Bandura, Annual Review of Psychology 52, 1-26 (2001)

19. Z. Bauman, Individualized Society (Logos, Moscow, 2005)

20. E. Razinkina, Polytechnic through the Eyes of Students: Education, Science, Politics. Almanac of sociological research 2016-2017 (Publishing house Polytechnic University, St. Petersburg, 2017) DOI: https://elibrary.ru/item.asp?id=35364835

21. Employers and educational institutions. How to achieve interaction? https://spb.hh.ru/article/22034

22. Yu.B. Stepanova, Vestnik PAGS 18(2) (2018) DOI: 10.22394/1682-2358-2018-2-95103

23. A.Yu. Myagkov, Sociological studies J. 6, $102-109 \quad$ (2016) http://socis.isras.ru/files/File/2016/2016_6/Myagkov.pdf

24. Yu.E. Kazakova, O.V. Okhotnikov, J. Human Resources and Intellectual Resources Management in Russia 7(5), 66-69 (2018) https://elibrary.ru/item.asp?id=36399716

25. S.L.C. Ottonicar, P.M. Arraiza, F. Armellini, J. Foresight and STI Governance 14(4) (2020) DOI: 10.17323/2500-2597.2020.4.95.111 